\title{
DE SURINAAMSE LANDBOUW
}

LESSEN UIT HET VERLEDEN BIJ EEN NIEUW BEGIN

I

DOOR

IR. J. FLOOR

INLEIDING.

Gedurende zijn werkzaamheden ten behoeve van de steunverlening en voorlichting van de Surinaamse plantagelandbouw heeft het de schrijver telkens weer getroffen hoe gewassen als Liberia-koffie, grapefruit, lemmetjes, citroenen en sinaasappelen groeiden en bloeiden bij een behandeling, die volgens begrippen van elders als mishandeling gekwalificeerd zouden moeten worden. Blijkbaar vinden deze gewassen buitengewoon gunstige groeivoorwaarden in de Surinaamse bodem.

Men zou nu verwachten, dat de Surinaamse landbouw, dank zij de gegeven omstandigheden, zich wel ontwikkeld zou hebben tot een welvarende en winstgevende cultuur. Wel zijn ook hier grote moeilijkheden te overwinnen, doch elders is dit niet anders, want geen cultuur is denkbaar zonder overwinning van talloze moeilijkheden. De geschiedenis van de Surinaamse plantagelandbouw biedt wel een geheel ander beeld. Verschillende cultures, zoals suiker, arabicakoffie, katoen en cacao hebben een gouden tijd gekend, maar na korter of langer tijd begon de achteruitgang en verdween de cultuur, om weer plaats te maken voor een nieuw gewas. Alleen suiker de oudste der Surinaamse cultures, heeft zich kunnen handhaven, zij het ook met grote schommelingen.

Thans is ook aan de cultuur van Liberia-koffie een einde gekomen en weer zijn er grote plannen voor een nieuw begin.

De vraag naar de oorzaken van al deze tegenslagen en mislukkingen in het verleden is de aanleiding tot deze studie geweest. Zijn eenmaal de in het verleden gemaakte fouten onderkend, dan is daarmede het inzicht verhelderd over de koers, welke in de toekomst gevolgd dient te worden. Deze les der geschiedenis, 
waarin de ervaringen van vroegere planters ons tot lering strekken, zal wellicht van waarde kunnen zijn voor degenen, die thans zullen bouwen en planten in het Surinaamse.

Ten behoeve van een overzichtelijk geheel zal de geschiedenis der plantage-cultuur en het commentaar van de schrijver behandeld worden onder de hoofden bodem, arbeid, kapitaal en bedrijtsvorm. De verkregen conclusies zullen tenslotte getoetst worden aan de resultaten van recent landbouw-economisch onderzoek, dat betrekking heeft op een soortgelijke bedrijfsvorm als die der Surinaamse plantages.

BODEM.

,Soil fertility must always be the foundation upon which permanent agricultural prosperity can alone be built ${ }^{1)}$.

Wat allereerst opvalt is het feit, dat in Suriname, onder tropische omstandigheden, de landbouw uitgeoefend wordt in polders. In de kuststrook waar de plantages voorkomen, is bedijking noodzakelijk om zowel het zoete als het zoute water te keren. Voor de lozing van het overtollige water van de zware regenval binnen de plantages wordt geprofiteerd van de ligging van het land boven de eblijn van de zee. De getijdewerking doet zich namelijk ver stroomopwaarts in de rivieren gelden, vandaar, dat alle plantages langs de rivier gelegen zijn om bij eb te kunnen spuien. Door deze omstandigheden is het binnenlands transport buitengewoon goedkoop, temeer, daar hierbij ook geprofiteerd kan worden van de getijdewerking der rivieren. Hoe groot dit voordeel is wordt pas duidelijk, wanneer men vergelijkt met de hoge transportkosten, die men elders vaak betalen moet.

Daarentegen heeft de noodzaak het land te bepolderen tot gevolg, dat de cultuur bezwaard wordt met grote extra-uitgaven voor aanleg en onderhoud van de polders. Men zal misschien zeggen, dat sinds er geen uitbreiding meer plaats heeft, wel de kosten voor onderhoud van sluizen, dammen en kanalen op de exploitatie-rekening komen, doch dat de aanlegkosten reeds lang afgeschreven zijn. Dit is zeer zeker waar, maar toch laat deze post zich nog gelden, in zoverre zij de terreinkeuze beperkt tot het land binnen de polder, waardoor men niet zoals overal elders, de meest geschikte gronden kan kiezen. Zo heeft bijvoorbeeld de citrus-aanleg op de plantages meestal plaats gehad op gronden,

1) Sir R. George Stapledon and William Davies, Ley Farming 1941, blz. 13 . 
die om de een of andere reden vrij waren voor cultuur. Ook bij de aanleg van Liberia-koffie valt een dergelijke gang van zaken vast te stellen. Zo schreef SNELLEN in dit verband: „De hierboven beschreven omzetting der cacaoteelt in koffie bewees opnieuw een der grote bezwaren van het plantagebedrijf, het gebrek aan grond wegens de beperking daarvan tot het ingepolderde terrein, waarvan in de eerste plaats het reeds bedolven, d.i. op lozing gebrachte gedeelte wordt gebruikt, daar de finantiële toestand in de meeste gevallen een verdere uitbreiding daarvan in de weg stond (17, blz. 107).

De Surinaamse cultuurgronden vallen tevens op door hun buitengewone compactheid. De kleifractie bedraagt in de regel niet minder dan $90-95 \%$. Voordat deze gronden ingepolderd werden stonden zij onder water, zodat er humusvorming plaats kon hebben. Voor het behoud van een goede structuur is het absoluut noodzakelijk dit gehalte aan organisch materiaal in de bodem op peil te houden. Het traditionele middel hiertoe is het inplanten van schaduwbomen. Doch in de dagen van de arabica-cultuur kende men het gebruik van schaduwbomen nog niet (18). Welke fatale gevolgen dit gehad heeft, blijkt wel uit het volgende citaat van BLom: ,de Beplanting was in nieuwe Landen, die vet en vrugtbaar waren, daar de Gewassen zeer voordeelig in groeiden, en vrugten opleeverden ... de Aarde nog nieuw zijnde was met een Groei Korst (onder de naam Veenaarde bekend) bezet, die lugtig, en droog, ligt, en zeer gemakkelijk van Onkruid te zuiveren is ... na meerdere Jaaren begonnen de eerst ontgonnen Gronden in Krachten afteneemen, de Gewassen verschraalden, besloegen minder de Grond, de bovenkorsting van Veenaarde verteerde, een bloote taaie, gesloote, compacte Klei, daar Zouten, Olie en balsemique vette vrugtbaare Deelen uitgeteerd waren, daar geen water uitzypelen of laxeeren konde, bleef alleen overig, het Onkruid kreeg meer en meer Lucht groeide sterker aan, de Arbeid vermeerde en wierdt zwaarer, en de Revenuen verminderden ... Eindelijk de Gewassen gingen uit, en de aarde te veel uitgebouwd ... wordt een nare dorre wildernis, daar ze buiten spitten of ploegen Eeuwen lang dor en onvrugtbaar in voort blijft duuren" (5, blz. 39).

Naar de ervaring sindsdien geleerd heeft kan een goede structuur op uitnemende wijze geconserveerd worden door het inplanten van Surinaamse koffiemamma's (Erythrina glauca). Doch niet altijd kan in dezelfde mate geprofiteerd worden van de voortreffelijke eigenschappen der Erythrina's. Bij een gewas als ca- 
cao, dat een zware schaduw verdraagt, kunnen de schaduwbomen dicht opeen geplant worden, zodat een dicht bladerdek de bodem beschermt en bij het vallen der bladeren de bodem verrijkt met organisch plantenmateriaal. Bij de citruscultuur is de situatie echter enigszins anders. Dit gewas verdraagt hoogstens een lichte schaduw; bovendien is het klimaat voor citrus eigenlijk toch al te vochtig, zodat ook om deze reden de schaduw zoveel mogelijk beperkt moet worden. Vandaar dat de schaduwbomen eerst 2 tot 3 jaren na aanleg ingeplant worden en de plantafstand zeer ruim genomen wordt. Bovendien zullen de bomen, met het oog op het gevaar voor schimmelinfecties hoog opgetrimd moeten worden. De schaduw zal dus bij de citrus-cultuur lang niet die bodemconserverende functie kunnen vervullen als bij de cacao-cultuur zodat men dan meer aangewezen zal zijn op het gebruik van groenbemesters. Niet altijd slaan zij gemakkelijk aan op deze zware, fosfaatarme kleigronden, doch na een grondbewerking lukt het als regel wel.

Van groot belang, ja eigenlijk de eerste voorwaarde voor het in stand houden van een goede structuur, is een goede drainage. Hoewel enkele cultuurgewassen, met name Liberia-koffie, een verregaande verwaarlozing in dit opzicht kunnen verdragen, reageren toch alle gewassen heel gunstig op een verbetering der lozing. De vraag dringt zich op, wat zal het effect zijn, indien de drainage dusdanig geperfectioneerd wordt, dat dit een belangrijke vergroting van de bouwkruin tengevolge heeft. In dit verband is het volgende van belang. Op iedere plantage is waar te nemen, dat koffie op de dammen beter produceert en een langere levensduur heeft dan in het veld. Algemeen verklaart men dit verschil door aan te nemen, dat de uit de loostrenzen opgeworpen grond der dammen vruchtbaarder is dan die van het veld.

Uit een proef van IR. DE KRAKER ${ }^{1}$ ) valt evenwel af te leiden, dat deze veronderstelling geen afdoende verklaring biedt. Het bleek namelijk, dat bacoven op dammen van grond uit het veld eveneens een hogere opbrengst gaven dan planten in het veld. Waarschijnlijk zijn daarom de hogere producties toe te schrijven aan de betere structuur van de dammen en aan de hogere ligging ten opzichte van de waterstand, waardoor een diepere bouwvoor verkregen wordt. Een diepere bouwvoor over het gehele veld zou verkregen kunnen worden door de lozing te perfectioneren of, nog verder gaande, het land onder bemaling te brengen.

1) mondelinge mededeling. 
Een goede bodemverzorging is ook in ander opzicht van belang. Suriname heeft een niet ongunstige regenverdeling waardoor cultuur zonder irrigatie mogelijk is. Voor een gewas als koffie, dat een uitgesproken droge tijd vraagt, is het Surinaamse klimaat stellig goed te noemen. Niettemin laat de droogte zich soms geducht gelden, en dit des te sterker, naarmate de bodemstructuur ongunstiger is. Ten onrechte wordt hierdoor in tijden van achteruitgang de schijn gewekt als zouden de seizoenen steeds onregelmatiger worden.

Behalve de instandhouding, verdient ook het herstel van de vruchtbaarheid van de bodem de volle aandacht. Vele plantagegronden vertonen een achteruitgang in vruchtbaarheid, maar aangezien zij reeds tot het poldergebied behooren, is algehele afschrijving zeer bezwaarlijk.

De meest natuurlijke wijze waarop het herstel van de bodemvruchtbaarheid plaats kan vinden is wel het toepassen van de natte braak. Het land wordt hierbij onder water gezet, waardoor er veenvorming plaats heeft en de vruchtbaarheid op dezelfde wijze hersteld wordt, als zij eertijds ontstaan is. In Demerara wordt natte braak geregeld toegepast, zoals wel blijkt uit het volgende citaat van de Directeur van de Landbouw aldaar ${ }^{1}$ ): ,The soil research work of the Departement embraces the study of the effects of flood-fallowing, a practice which had its beginnings locally as a pest control measure and which has developed to such an extent as to have become one of the most important field practices. Its value as a soil improver is no longer in doubt even though how it actually works still requires complete elucidation".

In de crisisjaren voor de oorlog heeft er aan een goed bodemonderhoud wel zeer veel ontbroken. Men meende dit straffeloos te kunnen doen, daar de ervaring geleerd heeft dat de bodem de cultuurgewassen buitengewoon gunstige groeivoorwaarden biedt. Een dergelijke bedrijfsvoering moge een tijdelijke verlichting van de moeilijkheden brengen, op de duur brengt zij de cultuur steeds dieper in het moeras. Blijvende welvaart kan alleen gebaseerd zijn op de instandhouding van de vruchtbaarheid van de bodem.

1) Brit. Guyana Dep. of Agr. Sugar Bull. no 4, 1935. 
ARBEID,

$\ldots$,the test of efficiency is not the amount per acre but the amount that can be grown with one man's labour" 1).

Suriname heeft, als zo menig Amerikaans land, een zeer geringe bevolking. De eerste kolonisten hebben nog getracht de autochthone bevolking als werkkrachten te exploiteren, echter zonder succes. De ontwikkeling van de landbouw als grootbedrijf werd eerst mogelijk door de aanvoer van slavenarbeiders. Geheel in tegenstelling tot de gangbare opvatting, valt uit de literatuur af te leiden, dat de slavenarbeid duur geweest is. Als gevolg van het monopoliestelsel van de West-Indische Compagnie waren de vrachtprijzen zeer hoog, waardoor de prijs der slaven hoog was en hun levensonderhoud duur (3,2 en $10 \mathrm{blz} .7$ en 8 ).

In het midden der vorige eeuw, nog voor de afschaffing der slavernij, is de immigratie van Aziatische werkkrachten begonnen. Deze immigratie van zeer verre afstand belastte de plantages heel zwaar; per immigrant betekende de aanvoerkosten een aanzienlijke verhoging van het dagloon. Een zeer nadelige omstandigheid was verder het ontbreken van een bevolkingsreservoir, waaruit men in de oogsttijd voldoende arbeiders kan betrekken. $\mathrm{Na}$ het verdwijnen van de cacao als plantagecultuur, welk gewas een andere oogsttijd heeft dan Liberia-koffie, liet deze ongunstige omstandigheid zich in haar volle zwaarte gelden.

Sinds 1927 zijn de immigratiekosten voor rekening van het Gouvernement. De oorspronkelijke bedoeling van arbeidersvoorziening van de groot-landbouw kwam evenwel geleidelijk op de achtergrond, terwijl kleinlandbouwkolonisatie meer bewust het doel van de immigratie werd.

Men heeft het belang ingezien van een vrije arbeidersbevolking op en in de nabijheid van de plantages. Deze arbeiders kregen de beschikking over een woning en een stuk grond om rijst te planten en andere voedingsgewassen, bovendien hadden zij vrije geneeskundige behandeling. Hiervoor waren zij verplicht een aantal dagen per week te werken.

Voor een aanvullend contingent arbeiders in oogsttijd of voor speciale werkzaamheden was men aangewezen op de kleinlandbouwers van de nabijgelegen vestigingsplaatsen, die op bepaalde tijden een aanvullend inkomen buiten hun bedrijfjes wensen te verdienen.

Kan men over de plantage-arbeiders ten alle tijde beschikken,

1) Sir A. DANIËl HAll: Reconstruction and the Land, 1941, blz. 90. 
op de arbeiders van buiten valt geen staat te maken, hun werkwilligheid verandert met de omstandigheden. Zo is bijvoorbeeld in de plant- en oogsttijd, of ook in een goed rijstjaar de animo voor het werken op de plantages gering.

In de achterliggende crisisjaren voor de oorlog namen de arbeidersmoeilijkheden steeds ernstiger vorm aan. De plantages konden door hun financiële moeilijkheden geen geregelde arbeid verschaffen en moesten bovendien tot loonsverlaging overgaan. Daarentegen werden de vooruitzichten voor de kleinlandbouwer steeds gunstiger. Het gevolg was dat de plantages steeds meer ontvolkt werden, temeer daar vele arbeiders gebruik maakten van de mogelijkheid, om zich als kleinlandbouwer te vestigen op domeingrond buiten het plantage-gebied. Zo raakten de plantages geleidelijk meer aangewezen op de tijdelijke arbeid van kleinlandbouwers - van mensen dus, op wier werkwilligheid men geen staat kan maken.

Uit het hier geschetste beeld van de arbeidstoestanden der plantages blijkt wel, met welke schier onoplosbare moeilijkheden iedere vorm van ondernemingslandbouw te maken zal krijgen. Men zal zich dan ook ter dege hebben te bezinnen over de wijze, waarop men deze moeilijkheden zo goed mogelijk het hoofd kan bieden.

Gaan wij thans na, wat er gedaan kan worden om het arbeidsprobleem tot een enigermate bevredigende oplossing te brengen. Het belang van deze kwestie is duidelijk, want hetgeen in dit opzicht bereikt kan worden, bepaalt in de gegeven omstandigheden de kans op een welvarende cultuur.

Momenteel staat mechanisatie wel in het brandpunt der belangstelling. Toepassing van dit principe zou tot een zeer welkome besparing van arbeid voeren, doch welke mogelijkheden er in deze richting liggen kan de schrijver niet beoordelen ${ }^{1}$ ).

Een zeer belangrijke arbeidsbesparing zal verkregen kunnen worden door het voeren van een doelmatig beleid. In dit verband kan het volgende opgemerkt worden. Men heeft het in Suriname als een vaststaand feit aangenomen, dat bij een chronisch tekort aan arbeiders, men vanzelfsprekend aangewezen zou zijn op extensieve cultuurmethoden, omdat dan het geringste aantal arbeiders per oppervlakte in cultuur nodig zijn. Een dergelijke opvatting voert uiteindelijk tot aanplantingen van verspreid in

1) Men zij voor deze aangelegenheid verwezen naar de nummers 3 ! en 33 van de literatuurlijst. 
het wied staande bomen, met geringe producties, welke zelfs de kosten voor het plukken niet kunnen opbrengen.

De enig juiste beperking van de arbeid moet dan ook niet gezocht worden in een beperking van het aantal arbeiders per oppervlakte in cultuur, doch in een beperking van de arbeid per eenheid product. Een dergelijke beperking van de arbeid, loopt parallel met een verlaging der productiekosten, aangezien deze kosten voor het allergrootste gedeelte uitgegeven worden in de vorm van arbeidslonen.

Gaan wij thans na welke maatregelen er toe zullen leiden dat de arbeid per eenheid product tot een minimum beperkt blijft.

De arbeid per eenheid product kan belangrijk verminderd worden, door de productie per oppervlakte op te voeren, omdat zodoende de arbeid voor aanleg en cultuuronderhoud, per eenheid product gerekend, afneemt. Om slechts enkele voorbeelden te noemen: Kan eenzelfde productie verkregen worden van een kleinere oppervlakte, dan zijn het aantal vrucht- en schaduwplanten dat geplant en onderhouden moet worden geringer. Ook behoeft dan voor eenzelfde productie een geringer oppervlakte schoon gehouden te worden van wied. Daarbij komt nog het voordeel, dat in een gesloten veld, het wied minder kans tot ontwikkeling krijgt. Ook is de arbeid, nodig voor de pluk, geringer in een goed producerend veld, dan wanneer eenzelfde productie binnengehaald moet worden van een grotere oppervlakte.

Verder mag veilig aangenomen worden, dat extra kosten voor toezicht om een volledige aanwending van de arbeidskracht te waarborgen en alle vormen van arbeidsverspilling te voorkomen, een rendabele uitgave zal zijn. Al deze maatregelen om de productie per oppervlakte op te voeren en de controle op de arbeiders uit te breiden, vormen met elkander een intensieve bedrijfsvoering.

Het gestelde doel, van minimale arbeidsaanwending per eenheid product zal bereikt worden bij een bepaalde graad van intensivering. Verdere intensivering zal dan toenemende arbeid, per eenheid product gerekend, tengevolge hebben, alsmede een stijging der productiekosten. Om te kunnen beoordelen hoever men met de intensivering der werkmethoden gaan moet, is het noodzakelijk een boekhouding te voeren, welke een overzicht van het bedrijf tot in bijzonderheden mogelijk maakt.

Intensieve werkmethoden passen zich op een gelukkige wijze aan bij Surinaamse omstandigheden, daar zij er toe leiden het aantal benodigde seizoenarbeiders te beperken. Immers in een 
intensief bedrijf zijn vele werkzaamheden in tijden van slapte er op gericht het werk in de oogsttijd te verlichten. Zo kan bijvoorbeeld buiten de oogsttijd gezorgd worden voor goede verbindingswegen in de plantage. Tijdens de pluk heeft dit een aanzienlijke arbeidsbesparing tengevolge, omdat het transport nu zoveel vergemakkelijkt is. Hetzelfde geldt voor tal van werkzaamheden, zoals bijvoorbeeld de arbeid die besteed wordt aan een goede kroonvorming bij citrusgewassen. Het is een werkverschaffing voor slappe tijden, welke, afgezien van andere voordelen, tot gevolg heeft, dat de arbeid in het drukke seizoen verminderd wordt, omdat de pluk nu gemakkelijker is geworden.

Behalve een bedrijfsvoering, welke het aantal seizoenarbeiders zo gering mogelijk tracht te houden, zouden maatregelen overwogen kunnen worden, welke het mobiel maken van de in het land aanwezige werkkrachten beogen. Bij een grondige kennis van het inheemse bedrijf zal het, meer dan tot nu toe het geval was, mogelijk zijn om de arbeidersvoorziening der plantages te regelen in overeenstemming met de economische behoeften van de kleinlandbouwer.

Maatregelen welke de werkwilligheid schaden, dienen vanzelfsprekend zo veel mogelijk vermeden te worden. Ook in dit opzicht biedt een intensieve bedrijfsvoering uitzicht op verbetering. Immers een doelmatige arbeidsaanwending als voornaamste factor in beperking der productiekosten, stelt het bedrijf op een gezonde basis, waardoor het mogelijk wordt om reserves aan te leggen voor tijden van tegenspoed. Bezuinigingen in de vorm van drastische loonsverlagingen of het ontslaan van arbeiders, zullen dan voorkomen kunnen worden. Het is duidelijk dat dit de werkwilligheid ten goede zal komen. Zo zijn bijvoorbeeld ontslagen arbeiders meestal voor goed verloren voor plantage-arbeid, want, zijn zij eenmaal vervreemd van de plantages, of hebben zij zich gevestigd als kleinlandbouwers, dan is het in de regel onmogelijk hen later weer terug te winnen voor plantage-arbeid.

Intensivering van het bedrijf, gaat vaak gepaard met een gewijzigde keuze der gewassen.

Gaan wij tenslotte na op welke wijze de keuze van een nieuwe cultuur het arbeidersvraagstuk zal beïnvloeden.

Met de cultuur van Liberia-koffie wordt het voortbrengen van een goedkoop product bereikt. Goedkoop, omdat geconcureerd moet worden met productiegebieden, waar de arbeidsvoorziening belangrijk beter is dan in Suriname, in verband waarmede aldaar lage lonen betaald kunnen worden. Bovendien is I.ibe- 
ria-koffie van een minder goede kwaliteit, wat de prijs ongunstig beïnvloedt en verder tot gevolg heeft, dat slechts enkele markten zich voor dit product interesseren.

Zouden echter de gunstige groeivoorwaarden van het land uitgebuit kunnen worden door een cultuur van waardevolle vruchten, dan zijn de vooruitzichten ongetwijfeld aanmerkelijk beter. Een cultuur van citrusvruchten bijvoorbeeld heeft te concureren met subtropische productiegebieden, waar zowel de lonen als de cultuurkosten hoog zijn. Eerst deze omstandigheid maakt het mogelijk om een loonpolitiek te voeren, waarvan verwacht mag worden, dat zij het arbeidersvraagstuk tot een redelijke oplossing zal kunnen brengen. Want er zullen dan lonen uitbetaald kunnen worden, welke een zekere welvaart onder de arbeiders brengen en welke ook voor welvarende kleinlandbouwers aantrekkelijke voorwaarden vormen.

KAPITAAL.

Capital, the soul of enterprise.

Uit de interessante gegevens over de opkomst en eerste ontwikkeling van de plantages valt af te leiden, hoe in de goede oude tijd het kapitaal vertrouwen stelde in de plantage-cultuur.

Zo lezen we in HerLein's „Beschrijvinge van de Volk-Plantinge Zuriname” van 1718: „De Eigenaars der Plantagien ... kunnen rijkelijk van de zelve bestaan ... want ... 't land geeft niet alleen de Hoofd-Zomme tot des zelfs Beplanting wederom, maar brengt bovendien in korten Jaren zeer aanmerkelijke schatten tot overwinst op, waar van men genoeg levendige voorbeelden heeft, aan Luiden die zelve niet veel gehad hebben, en alles voornamelijk hebben moeten aanleggen en beginnen, met het behulpzaam Credyt dat de Edele Maatschappij de nieuwe Planters verleent, hoe ze in weinige Jaren uit de opgeleide schuld geraakt zijn, en een vrije rijke staat bezitten".

Naast suiker, de hoofdcultuur van die dagen, nam de cultuur van de Surinaamse koffie een aanvang.

Naar Floris VisSChER HeshuYsen meedeelt ontwikkelde deze cultuur ,zig eerst langzaam doordien zoo wel het vermogen als het crediet van de meeste planters bepaald was, en zij natuurlijk hunne suikerplantagien als hunne hoofdzaak bleven aanzien". (3, blz. 191).

De grote uitbreiding is gekomen, toen na het midden der $18 \mathrm{e}$ eeuw de koffieprijzen buitensporig hoog opliepen. Het gevolg was, dat men naar uitbreiding van zaken streefde. Het daarvoor be- 
nodigde kapitaal werd gaarne door de Nederlandsche, in het bijzonder de Amsterdamse handel verstrekt (12, blz. 505). De planters werden ,,van alle kanten met geld en crediet als overstelpt" (3, blz. 92). Want de directies der negotiatien presten hunne agenten in Suriname om zoveel mogelijk hypotheken te plaatsen. De leningen beliepen tot een maximum van $5 / 8$ van de geschatte waarde der plantages. Maar bij de taxaties werd veel geknoeid (12, blz. 505). De nieuwe eigenaars ,,veelal onkundig in planten, en verblind door de hooge prijzen van de Coffy, hadden geen vermoeden dat deeze vijf achtste reeds meerder bedroeg dan de plantagie voor den kooper waardig was. integendeel droomde ieder niet dan van een spoedig fortuin, men ontzag geene kosten zoo aan zijne gebouwen als in zijne huishouding niets was te kostbaar voor Suriname ..." (3, blz. XIV).

Het is duidelijk dat dit alles vroeg of laat spaak moest lopen. Daarenboven lieten de gevolgen van een kortzichtig beleid zich gelden. Men plantte 100-, 150- of soms 200000 bomen en ,stelde zig voor om het daarbij te laten, en zijn fortuin van de vruchten van dezen arbeid af te wachten" (3, blz. 193).

In de grote begerigheid om maar zo gauw mogelijk ,,binnen” te zijn werd wel met koortsachtige haast uitgebreid, maar werd weinig gedaan om de aanplant in stand te houden. En daar de cultuur zonder schaduw gedreven werd, begon de vruchtbaarheid van de bodem na vijftien jaren al af te nemen (5, blz. 83). De producties werden steeds minder, terwijl daarentegen de kosten voor onderhoud, vooral wieden steeds toenamen. Toen de koffieprijzen terugliepen lieten de hoge lasten en de snel afnemende inkomsten meestal geen geld meer om de achteruitgang afdoende te stuiten. En toen de terugbetaling der schulden stokte werd het crediet wantrouwig. Vele planters zijn hun plantages kwijt geraakt om hun schulden aan te zuiveren. Het behoeft geen betoog dat de geldschieters grote kapitalen verloren hebben.

De geschiedenis heeft zich in velerlei opzichten herhaald. Ieder der volgende cultures werd met weinig kapitaal aangevangen. Immers zij moesten opgebouwd worden uit de resten van een verdwijnende cultuur. Het gebrek aan bedrijfsmiddelen heeft ertoe geleid, dat, evenals bij de arabica-cultuur in sterke mate het geval was, bij aanleg en onderhoud te veel op ogenblikkelijke voordelen aangestuurd werd. Een dergelijk beleid moet zich op de duur wreken, want voor meerjarige cultures is het voeren van een politiek op lange termijn noodzakelijk. Ook werd wel eens een nieuwe cultuur met een al te grote haast uitgebreid. De moei- 
lijke omstandigheden, waaronder men naar een spoedige vervanger van een snel achteruitgaande cultuur moest zoeken, maken het gevoerde beleid heel begrijpelijk, de fatale gevolgen van een onvoldoende voorbereiding bleven evenwel nimmer uit (11 en 13). Slechts in tijden van abnormaal hoge prijzen bracht de landbouw welvaart in het land. Dooreengenomen echter heeft het kapitaal in de Surinaamse landbouw stellig een weinig voordelig beleggingsobject gevonden, zo er al geen sprake is van verlies.

De geografisch-economische positie van Suriname werd, vergeleken bij vroeger, steeds minder. In tegenstelling met andere landbouwgebieden kwam het land buiten de druk bevaren scheeps routes te liggen en het grote voordeel van het buitengewoon gemakkelijk binnenlands transport nam in betekenis af, toen de uitvinding van de machine de transport-mogelijkheden geweldig uitbreidde, waardoor het elders mogelijk werd tegen berghellingen of honderden kilometers het oerwoud' in, een rendabele cultuur te drijven. Ten aanzien van Oost-Indië kwam Suriname verder in het nadeel door de opening van het Suez-kanaal, de nieuwe agrarische wetgeving en de snelle bevolkingsaanwas van Java (19 en 20).

Terwijl de omstandigheden voor Suriname steeds minder gunstig werden, is de mededinging gekomen van tal van agrarische landen alsmede van de bevolkingscultures, waardoor de prijzen zich thans op een aanzienlijk lager niveau bewegen.

Andere ongunstige factoren, vooral de moeilijkheden met de arbeidersvoorziening, maakten Suriname steeds meer tot een land van dure productie, zodat het kapitaal elders een dankbaarder beleggingsobject vond (19 en 20).

De interesse van het kapitaal was in de jaren voor de oorlog geringer dan ooit (23, blz. 4 en 5). De plantage-landbouw werd dan ook voor een steeds groter gedeelte gefinancierd met gouvernementsgelden.

Wil men ooit weer het particuliere kapitaal interesseren voor de Surinaamse plantage-landbouw, dan zal eerst een oud en diep geworteld wantrouwen overwonnen moeten worden. Dit is alleen mogelijk door metterdaad aan te tonen, desnoods op kleine schaal, dat de grootlandbouw in Suriname wel degelijk een voordelig en aanlokkelijk beleggingsobject voor het emplooi zoekend kapitaal kan zijn. Tot de tijd dat dit bewijs geleverd is, blijft de Surinaamse landbouw aangewezen op kapitaalsvoorziening door de Overheid. 
BEDRIJFSVORM.

\author{
,If farming is in a bad way, it is more important to \\ remove the causes of the decline than to pay the far- \\ mers' losses and enable them to carry on as they have \\ been doing" 1 ).
}

Zoals uit de achttiende-eeuwse literatuur blijkt, werden de Surinaamse plantages in de regel met uiterst beperkte middelen opgezet. (1, blz. 83). Vele planters waren gewezen soldaten die na afloop van hun diensttijd hun fortuin trachtten te maken in de landbouw (3, blz. 354).

Vaak werd begonnen met 6, 8 of 10 slaven een zogenaamde kostplantage aan te leggen om voedingsgewassen aan te planten, welke verkocht konden worden in de stad Paramaribo of aan de suikerplantages voor de voeding der slaven (1, blz. 84). De plantages zorgden toen dus voor de inheemse voedselvoorziening, welke taak thans door de kleinlandbouw vervuld wordt.

Beschikte men na verloop van tijd over wat meer contanten dan werd een voordeliger gewas als bijvoorbeeld koffie aangeplant en kon aan verdere uitbreiding gedacht worden.

Omtrent de grootte der plantages vinden we bij een Surinaams planter van 1740 opgegeven als beplant oppervlakte 100 akker (40 ha). HeshuYsen noemt de gewoonte om 100.000-200.000 bomen te planten, wat neer komt op 200-400 akker (3, blz. 192).

Uit de voortreffelijke werken van HESHUYSEN en Blom blijkt, dat er heel wat aan de bedrijfsopzet en bedrijfsvoering ontbroken heeft. Ondanks deze en ook andere bezwarende omstandigheden, zoals de hoge vrachtprijzen en de duurte van de slavenarbeid, zijn er vooral na het midden der 18de eeuw grote winsten gemaakt toen door een gunstige samenloop van omstandigheden, de prijzen buitengewoon hoog waren.

Toen later de prijzen terugliepen, hadden de fouten in de bedrijfsvoering een débacle tengevolge.

Er zijn andere cultures gekomen en gegaan. De opzet en organisatie der plantage-bedrijven veranderde evenwel slechts weinig. Reeds een eeuw geleden schreef LaNs (1842) hieromtrent: ,De omstandigheden zijn door de politieke en industriele gebeurtenissen zeer veranderd, terwijl het systema van productie in Suriname hetzelfde is gebleven. Zie daar, volgens mij, de oorzaak van het verval. Ene wijziging van het systema, berekend naar de vereisten van den tijd, is dus het geneesmiddel." Als

1) Sir A. DANï̈L HAll, Reconstruction and the Land, 1941 p. (Ix). 
eerste maatregel wordt ,een intelligente, op wetenschappelijke gronden berustende landbouw" genoemd (9, blz. 192).

Heden ten dage kan nog minder dan ooit, enig succes verwacht worden van ondernemingen met verouderde bedrijfsmethoden. Natuurlijk is het wel denkbaar, dat door een gunstige samenloop van verschillende omstandigheden tijdelijk enig voordeel verkregen wordt, maar op de duur hebben deze bedrijven geen kans in de strijd om het bestaan en zijn zij ten ondergang gedoemd.

De hedendaagse bedrijfsvoering der plantages wordt vóór alles gekenmerkt door een zeer ondoelmatige aanwending van de beschikbare arbeidersmacht. Tot illustratie moge het volgende dienen: Zoals reeds opgemerkt werd, wordt met de cultuur van Liberia-koffie een goedkoop product van minder goede kwaliteit bereikt. Tegenover dit nadeel staat echter het voordeel van de mogelijkheid van een buitengewoon grote productie per oppervlakte. Maar dit voordeel wordt bij lange na niet uitgebuit als gevolg van de extensieve cultuurmethoden bestaande uit het gebruik van ongeselecteerd plantmateriaal, slechte verzorging van de lozing, gering bodemonderhoud en onvoldoend inboeten.

Een nadeel van Liberia-koffie is verder, dat er relatief veel arbeid nodig is om de oogst binnen te halen. Eén van de redenen is het plukken in een aantal rondgangen. Met de extensivering der cultuur wordt dit nadeel groter en zal het percentage van de oogst, dat niet meer tegen lonende prijzen geplukt kan worden, toenemen.

Ondanks de grote moeilijkheden om aan voldoende seizoenarbeiders te komen werd een veel zorg vereisende bijcultuur van citrusvruchten aanvaard, die deze moeilijkheden nog weer zullen vergroten, omdat de oogsttijd geheel of grotendeels samenvalt met die van koffie.

Gering toezicht op het werk en veelal slechte verbindingswegen in de plantages dragen er verder toe bij de arbeidsverspilling te vergroten.

Trachten wij thans de oorzaken van deze verouderde bedrijfsvoering op te sporen. In het algemeen gesproken zal een landbouwer, uit welbegrepen eigenbelang, zich bij voorkeur houden aan oude welbeproefde werkmethoden. Op de duur leidt een dergelijke houding als vanzelf tot een verouderde bedrijfsvoering. Meestal echter dwingen de omstandigheden er van tijd tot tijd toe om door een reorganisatie van het bedrijf de bestaande achterstand geheel of gedeeltelijk in te halen.

In Suriname is de landbouw van zeer oude datum, zodat er 
gelegenheid te over is geweest voor een gevestigde traditie. Maar een stimulans om de bedrijfsvoering te verbeteren, naarmate nieuwere inzichten hieromtrent veld wonnen, heeft ontbroken of heeft althans nimmer doorgewerkt. Verschillende redenen zijn hiervoor aan te voeren. Toevloeiing van nieuw kapitaal van enige betekenis heeft niet meer plaats gehad sinds de geographischeconomische positie van Suriname in het midden der vorige eeuw gaandeweg minder werd ten opzichte van het Verre Oosten, alwaar het kapitaal een voordeliger beleggingsobject vond. Ook de stimulans welke er kan uitgaan van een gegeven voorbeeld heeft ontbroken. Een individuele poging om een nieuwe koers te volgen is in Suriname wel uiterst moeilijk vanwege het chronisch gebrek aan arbeiders en de omstandigheid dat het beschikbare plantareaal beperkt is tot de ingepolderde gronden.

Verder hebben de vele crises, welke in de loop der tijden voorkwamen, nimmer tot een herziening der bestaande bedrijfsmethoden gedwongen, daar het Gouvernement altijd weer bereid bleek om de geleden verliezen bij te passen, waardoor het mogelijk werd de plantages weer op de oude voet voort te zetten, zij het vaak met een ander gewas.

Tenslotte moet nog opgemerkt worden, dat ook de wetenschappelijke voorlichting geen noemenswaardige verbeteringen in de bedrijfsvoering ten gevolge heeft gehad. Sinds de ervaring van de funeste gevolgen van de panama-ziekte in de bacoven en de krulloten-ziekte in de cacao, werd het onderzoek van het Landbouwproefstation voornamelijk geconcentreerd op de in de cultuurgewassen voorkomende ziekten en plagen. Het op dit gebied verrichte werk heeft ook buiten Suriname een voortreffelijke naam. Mede in verband met bovengenoemde specialisatie en de uiterst beperkte middelen van het Proefstation in verhouding tot de vele vraagstukken van groot- zowel als klein-landbouw werd een economische studie van het plantage-bedrijf nimmer ondernomen, vandaar dat het Landbouwproefstation ook geen richting heeft kunnen geven aan het gevoerde beleid.

In de vooroorlogse crisisjaren werden de door de Regering genomen maatregelen tot steun aan- of sanering van de koffiecultuur uitgevoerd door een semi-officiele instelling, de Surinaamse Koffiecentrale, bijgestaan door het Departement van Economische Zaken, welke aanvankelijk een afdeling van het Landbouwproefstation was. Naar beste vermogen werd getracht de plantagelandbouw door een uiterst moeilijke periode heen te helpen. Onevenredig sterke bezuiniging op cultuuronderhoud 
werd in vele gevallen voorkomen, maatregelen tot centralisatie van de koffiebereiding werden ondernomen en de aanleg van citrus als bijcultuur werd mogelijk gemaakt.

Als geheel echter bewoog het gevoerde beleid zich te veel in de traditionele lijn om het plantagebedrijf op een gezonde basis te brengen. Het meest te betreuren feit is wel dat een zo veel belovende cultuur als die van citrus veelal begonnen werd op de verspreid in de plantages liggende velden, welke om de een of andere reden minder geschikt waren voor cultuur. Zonder twijfel wordt op deze wijze de nieuwe cultuur begonnen onder de minst gunstige omstandigheden. In het verleden droeg ieder der in Suriname ondernomen cultures de kiem van mislukking in zich als gevolg van een onvoldoende voorbereiding en een al te overhaaste opzet. Het is dan ook te hopen dat thans voorkomen zal worden, dat de geschiedenis zich andermaal herhaalt.

Evenals LANS in 1842, moeten wij thans tot de conclusie komen, dat de oorzaak van het verval van de plantagecultuur, van de tegenslagen en mislukkingen in het verleden, gezocht moet worden in een verouderde en hoogst ondoelmatige bedrijfsvoering.

Het ware te wensen dat subsidies van de Overheid niet langer tot een bestendiging van een dergelijk beheer zullen leiden, doch dat integendeel de verstrekking van deze gelden, zal stimuleren tot een rationele bedrijfsreorganisatie.

(Wordt vervolgd). 